\title{
RITOS DE VELÓRIO E SEPULTAMENTO DE CRIANÇAS NA HISTÓRIA DA INFÂNCIA EM BELÉM DO PARÁ (1910-1914)
}

Carmeci dos Reis Viana ${ }^{1}$

Laura Maria Silva Araújo Alves ${ }^{2}$

\section{INTRODUÇÃO}

A infância vem se constituindo historicamente a partir dos estudos alavancados por dois grandes estudiosos e suas obras sobre a criança: de um lado, por Ariès, com a obra "A História Social da Criança e da Família"”; e de outro, por Heywood com a obra "Uma história da infância: da Idade Média à época contemporânea no Ocidente"4. Ambas as obras apontam que há preocupação pelo período da infância e afirmam que é um fenômeno moderno muito por conta dos poucos registros que se têm sobre as memórias e experiências de infância em épocas passadas, pois havia pouco interesse em conhecer principalmente as especificidades dos sujeitos nessa etapa da vida. Na sociedade medieval, por exemplo, a centralidade em assuntos religiosos retirou muitos temas do foco de interesse da época e a infância foi um deles. Além disso, o foco na vida adulta era predominantemente destacado em detrimento à infância.

Segundo Ariès, (1981), as crianças na Idade Média eram vistas como homens e mulheres de tamanho reduzido, como "adultos em miniatura", não havendo a consciência de que as crianças eram diferentes dos adultos. Nesse período, o modo de se vestir, as conversas, os jogos, as brincadeiras e até os trabalhos realizados pelas crianças eram praticamente os mesmos, não existia a separação entre

\footnotetext{
1 Mestranda em Educação pelo Programa de Pós-Graduação em Educação da Universidade Federal do Pará. Bolsista CNPq. carmeci.viana@hotmail.com

2 Professora doutora, da Universidade Federal do Pará. laura_alves@uol.com.br

3 Philippe Ariès nasceu em 24 de junho de 1914 e concluiu seus estudos de História na Sorbonne. É universalmente considerado um dos melhores historiadores contemporâneos no campo do estado de atitudes. Sua obra mais celebre é Sur l'enfant et la vie familiale sous l'ancient Régime, que traça a história da infância e da família moderna.

4 Colin Heywood explora as experiências da infância, da Idade Média à época contemporânea. O autor examina as diferentes formas em que as pessoas pensaram sobre a infância como etapa da vida, os relacionamentos das crianças com suas famílias e seus pares, e as experiências dos pequenos no trabalho, na escola, e nas mãos de várias instituições de bem estar. Aborda ainda aspectos culturais e socais que permearam a história da infância mundial da Idade Média até o período Contemporâneo.
} 
o universo infantil e o do adulto. Enfim, "essa infância muito curta fazia com que as crianças ao completarem cinco ou sete anos já ingressassem no mundo dos adultos sem absolutamente nenhuma transição" (ARIÉS, 1981, p.20).

Essa prerrogativa, conforme destaca Ariès (1981), estava diretamente associada com a alta taxa de mortalidade infantil, que fazia com que os pais não criassem grandes expectativas com as crianças, que poderiam facilmente vir à óbito, visto que não havia a consciência de que as crianças necessitavam de cuidados com vestimenta, alimentação e higiene, que fossem diferenciados dos adultos, fato que agravava as moléstias e mazelas que afligiam a infância nesse período. A falta de sentimentos de cuidados e de afetividade com a criança eram recorrestes, uma vez que, os pais perdiam seus filhos com as epidemias e moléstias que atingiam as crianças.

Com relação à infância no Brasil, as mazelas infantis perpassam pelos períodos históricos que vão da Colônia até a República. Sobre a infância brasileira, Rizzini (2009) sinaliza que com o advento da República, a situação da infância se tornou ainda mais problemática, com o intenso processo de imigração, de famílias que chegavam e tinham que disputar espaço com as que já habitavam a cidade. O crescimento urbano desordenado fez com que as famílias fossem levadas para bairros periféricos, onde havia escassez de água e saneamento, fatores preponderantes para as altas taxas de mortalidade infantil nas capitais. Neste contexto, a mortalidade infantil se afirmava como um obstáculo eminente à concretização dos ideais de ordem e de progresso instalado na República, sobretudo com o ideário de civilidade e modernidade para que o país saísse do atraso estabelecido pelo Império.

A história da Infância no Brasil e no Pará estão fortemente relacionadas aos ideários desenvolvimentistas da emergente república nacional, pois é a partir da necessidade de reformas urbanas, econômicas e sociais que se ascende o interesse e os cuidados com a infância. Neste sentido, a criança ganha mais visibilidade e maiores cuidados, pois passava a representar o "futuro da nação" (DEL PRIORE, 2000).

Sob esta perspectiva, os poderes públicos das capitais brasileiras importam um modelo de civilização da Europa, a partir do qual as políticas de higiene eram largamente difundidas. Deste modo, a elite intelectual do Brasil, juntamente com os poderes políticos desejavam o desenvolvimento da nação e passaram então a investir em medidas higienistas e sanitaristas para as capitais em razão de um modelo de urbanização que combatesse a mortalidade infantil e o abandono de crianças. Para tanto, regras passam a ser inseridas no cotidiano da população de modo individual e coletivo (GÓIS JR.; LOVISOLO, 2003). 
Embora com todo esse novo modelo de desenvolvimento nos cuidados da criança, as práticas culturais adotadas por famílias não deixaram de estar presentes em seus rituais diários, inclusive naqueles adotados na conservação da saúde e do desenvolvimento saudável das crianças. Del Priore (2000) descreve, por exemplo, práticas culturais presentes na infância brasileira como: (1) as crianças pequenas eram submetidas a alimentos considerados fortes para sua idade; (2) o hábito inadequado do tratamento com o cordão umbilical dos recém-nascidos e (3) as práticas de sepultamento no quintal das próprias casas para as famílias menos abastadas.

A pesar do pujante desenvolvimento econômico, social e político na modernidade das cidades e das políticas higienistas ${ }^{5}$ visivelmente implementadas com o advento da República, as taxas de mortalidade infantil ocupavam altos índices na primeira infância. Indiscutivelmente, com o movimento higienista, a criança tornou-se objeto privilegiado do projeto da Medicina Social, de acordo com o entendimento de que as outras fases da vida dependem dos cuidados com a criança, trazendo medidas profiláticas em relação à infância.

A política higienista da Belle Époque na Amazônia desdobrou-se ainda no espaço urbano em todo o Brasil. Dados levantados em Livros Perpétuos de Sepultamento de Menores no Cemitério de Santa Isabel em Belém do Pará, de 1910 a $1911^{6}$, demonstram que anos depois do raiar da República, que a mortalidade infantil alcançava ainda números alarmantes. O atraso que se instalou no Império não havia sido superado, sobretudo quanto à mortalidade infantil.

O texto está estruturado em duas partes. Na primeira abordamos a infância, as políticas higienistas e a mortalidade infantil em Belém do Pará, nos séculos XIX e XX, a partir da leitura de autores que fazem parte da historiografia da infância no Brasil e, em especial, de autores do Pará. Na

\footnotetext{
${ }^{5}$ Com advento republicano no Brasil, as principais cidades do país implementaram uma política de higienista de modernização que exigia de seus gestores ações concretas em espaço urbano e domiciliar, interferindo nos hábitos, costumes e relações sociais da população. A região Amazônica, na segunda metade do século XIX, vivenciou um período de grande riqueza econômica gerada pela exploração gomífera, o que contribuiu para a aplicação de um projeto reformador na capital paraense que objetivava combater à mortalidade infantil e os cuidados com a criança. Entre os anos de 1897 a 1911, a cidade de Belém do Pará passa a ser administrada pelo intendente Antônio José de Lemos ${ }^{5}$, o qual foi o principal responsável pela busca da modernidade e de um modelo civilizador para Belém do Pará.

6 A mortalidade infantil nos Livros de Sepultamento de menores nos anos de 1910 a 1914 foi uma pesquisa desenvolvida com a intenção de diagnosticar estatisticamente o óbito de menores, sobretudo as doenças causadoras da mortalidade infantil. Os Livros Perpétuos de Sepultamento de Menores são fontes de informações minuciosas que revelam, por exemplo, o nível de envolvimento da população com as ações higienistas em Belém, por meio de profissionais da saúde que foram responsáveis em atestar as causas mortis das crianças. Estes profissionais foram importantes para a medicina local como: Dr. Camilo Salgado, Dr. Augusto Montenegro, Dr. Amazonas Figueiredo, Dr, Pena de Carvalho e Dr. Ophir Loyola e outros
} 
segunda parte destacamos a relação da mortalidade infantil e os rituais do velório e sepultamento de crianças que entrelaçaram na cultura paraense de veneração da família diante da morte da criança.

\section{INFÂNCIA, HIGIENE E MORTALIDADE EM BELÉM DO PARÁ}

A passagem da criança pela família e pela sociedade era muito breve e muito insignificante para que tivesse tempo ou razão de forçar a memória e tocar a sensibilidade (ARIÈS, 1981, p. 21).

É sabido que a mortalidade infantil foi algo assombroso em todos os países do mundo, tanto é que Ariès em sua obra intitulada a "História Social da Criança e da Família" faz importantes abordagens acerca do tema. A citação acima pontua aquilo que contextualiza sua obra, no que se refere ao sentimento de infância, pois a brevidade da vida infantil no contexto social e familiar preconizava a hostilidade ou desapego aos infantes devido à fragilidade da vida da criança. Essa fragilidade estava associada ao meio em que viviam as crianças, mas também as condições a que estavam expostas nos primeiros anos de vida.

A mortalidade infantil na capital paraense causava preocupação para os reformadores da educação e intelectuais da saúde com a República. Em análises feitas nos Livros Perpétuos de Sepultamento de Menor do Cemitério de Santa Izabel na cidade de Belém, constatamos diagnósticos das principais doenças que ceifavam as crianças nos primeiros anos de vida7. Além disso, pontuamos que os altos índices de mortalidade estavam fortemente atrelados às questões de ordem social e econômica, pois o país e o Estado do Pará passavam por uma série de mudanças no que concerne à modernização das cidades com as políticas de saneamento e melhoria das condições higiênicas da população. A cidade de Belém, dos finais do século XIX, ainda vivia sob os efeitos da economia da

\footnotetext{
7 Do total de 4.697 óbitos de crianças nos anos de 1910 a 1914, a causas da mortalidade infantil mais recorrentes estavam associados a doenças digestivas e intestinais, às provenientes do precário acesso à água e às péssimas condições sanitárias em que viviam as famílias cujas crianças morriam. Conforme já apresentamos na tabela 2 sobre as idades de morte das crianças muitas morriam com idade entre horas de vida e um ano de idade. As doenças associadas a estas mortes, de acordo com a quadro 5, do total de 4.697 crianças falecidas de 1910 a 1914 a gastroenterite com 24\% (1.136) foi a doença que causou a mortalidade das crianças e a Infecção intestinal com 14\% (656) a segunda. As doenças relacionadas às infecções digestivas e intestinais eram apontadas pelos médicos como o grande causador da mortalidade infantil.
} 
borracha8, e, em consequência disso, famílias inteiras de imigrantes mudavam-se para a capital em busca de melhoria de vida e com elas suas crianças (VIANA, 2016).

As questões ligadas à infância vinculavam-se mais fortemente nos discursos nacionalistas, no sentido de que a criança era apontada como o "futuro da nação". Para tanto, era necessário que os assuntos que envolvessem a infância, sobretudo os cuidados com as crianças, tivessem um pouco mais de atenção. As oligarquias paraenses, juntamente com as autoridades políticas, investiam nas ligas saneadoras (política higienista9) no sentido de remodelar os cuidados com a saúde e higiene da sociedade, defendendo o ensino de novos hábitos higiênicos, já que consideravam a falta de higiene o principal problema da população no processo de desenvolvimento nacional.

\begin{abstract}
Os preceitos de higiene no Brasil estavam intrinsicamente ligados aos ideários desenvolvimentistas logo, tudo que fosse torto, desviante, baixo, era alvo da intervenção, pois o modelo europeu é que embalava o sonho de progresso da nação. Portanto, casas caindo aos pedaços, pedintes, ambulantes, mendigos e outros não podiam fazer parte do cenário das cidades, pois o que se queria era uma pátria essencialmente salubre, educada e higienizada, capaz de acompanhar o desenvolvimento dos países ricos e eliminar suas mazelas sociais (VIANA, 2016, p. 24).
\end{abstract}

Os preceitos de higiene permeavam as ações sociais, filantrópicas e de assistência nas principais capitais e centros urbanos do país ${ }^{10}$. Deste modo, as ações higiênicas são implantadas mais facilmente para as camadas sociais menos favorecidas, pois, uma vez entregues à filantropia, havia possibilidade de formação futura como se vê nas políticas higienistas.

Os higienistas estavam identificados com o movimento filantrópico, que travava um embate com os representantes da ação caritativa, nas primeiras décadas do século. A filantropia distinguia-se da caridade, pelos seus métodos, considerados científicos, por esperar resultados concretos e

\footnotetext{
${ }^{8}$ A exploração da borracha na Amazônia proporcionou uma economia forte na região que favoreceu o desenvolvimento de Belém do Para e Manaus no Amazonas. As duas cidades viveram um tempo de muita riqueza e que atraiu muitos imigrantes estrangeiros para a Amazônia. Sem dúvida, a região Norte foi favorecida pela comercialização da Borracha. 9 A política higienista surge no Brasil no século XIX, uma medida que corroboraria com o ideário de desenvolvimento da nação. A política tinha como principal intenção trazer hábitos tidos como saudáveis no tocante à educação e a higiene dos corpos (VIANNA, 2016. P. 22).

10 Em Belém do Pará, nos finais do século XIX e início do século XX, foram criadas várias instituições educativas que objetivavam abrigar meninos e meninas desvalidos como uma política higienista de evitar a criminalidade e o abandono de crianças que de certa maneira era incompatível com o ideário de civilidade.
} 
imediatos, como o bom encaminhamento dos desviantes à vida social, tornando-os cidadãos úteis e independentes da caridade alheia [...] (RIZZINI E PILOTTI, 2009, p. 22).

As políticas de higiene e prevenção se materializaram nas ruas e cidades com as ações dos médicos e sanitaristas, pois a intenção delineada era higienizar e disciplinar os membros das camadas menos favorecidas com o intuito de "limpar" as cidades. Havia preocupação com a saúde, por ser o Brasil dependente da economia externa, precisava se mostrar salubre e pronto para receber novos investidores, do mesmo modo que deveria zelar pelos seus portos, canal principal do desenvolvimento econômico (PINHEIRO, 2013).

Com vistas a produzir mudanças de comportamento na população brasileira, uma verdadeira cruzada higiênica mobilizava médicos, educadores, engenheiros e todos aqueles ligados, de alguma maneira, à causa da instrução pública. E nesta empreitada, as crianças eram alvo importante dos higienistas que consideravam "a infância como a idade de ouro para a higiene mental" (MELO; NASCIMENTO et al. 2012). Neste sentido, a criança passa a ser o campo promissor dos higienistas que já não se preocupavam apenas com a saúde física, mas também com a saúde mental, por isso a constante intervenção das autoridades sanitárias nos âmbitos escolar e familiar.

[...] o retrato do Brasil era pintado com pinceladas fortes e mostrava um povo doente e analfabeto, abandonado pelo Estado e entregue à própria sorte. Para eles, era urgente integrar essas populações nos marcos da nacionalidade e da cidadania, conferindo-lhes condições para a melhoria da própria vida [...] (PONTE, 2007, p. 76).

$\mathrm{Na}$ intenção de erradicar as epidemias e endemias que manchavam a constituição de nação forte e produtiva, os agentes governamentais, aliados a investidores cujo interesse se concentrava no desenvolvimento econômico e político do Estado, passam a investir nas ligas saneadoras para que a capital paraense ${ }^{11}$ acompanhasse o desenvolvimento das capitais do Brasil. Imbuídos por sentimento

11 Nos finais do século XIX a cidade de Belém do Pará vivia um neste cenário higienista que doentes, velhos, escravos e crianças que se encontravam nas vias públicas esmolando ou em situação de abandono incomodavam o grande reformador Antônio Lemos, ao ponto de estabelecer algumas medidas radicais de higiene, como por exemplo, a limpeza na cidade com a retirada dessa população pobre das vias públicas. Lemos tinha a intenção de fazer uma cidade mais salubre aos olhos dos estrangeiros. Houve então uma política de fiscalização com a atuação de agentes municipais na educação da população tanto que se estabeleceu a criação de "instituições civilizadoras" para abrigar crianças pobres e desvalidas e $\mathrm{o}$ asilo de mendicidade para acolher os velhos e indigentes. 
renovador, campanhas de limpeza e saneamento foram largamente difundidas na capital paraense com a intenção de "limpar" os centros da cidade.

A população infantil sofrera de tal forma ou em graus mais elevados que os adultos, pois suas fragilidades, por baixa imunidade a vírus e bactérias faziam com que além da febre amarela, doenças de ordem gastrointestinais fossem ameaçadoras ao seu ciclo de vida. Tal doença se configurava como inflamação aguda que, causada por vírus, bactérias e parasitas, era provocada por ambientes sem tratamento de água, rede de esgoto, água encanada e destino adequado para dejetos fecais (GUIMAR ÃES, 2016, p. 138).

A mortalidade infantil vitimava as crianças e está indubitavelmente relacionada à questão de higiene e saneamento da cidade, sobretudo aquelas ligadas ao acesso e consumo de água tratada. Os dados indicam que nos anos de 1910 a 1914 morreram cerca de 4.637 crianças em Belém do Pará e que atingiram meninos e meninas. As mortes se davam entre crianças com horas de nascidas até crianças entre 7 e 11 anos de idade (VIANA, 2016). Entre as doenças que causavam a mortalidade infantil em Belém do Pará estavam:

Em geral, as doenças associadas a estas mortes consistiam em debilidade congênita com cerca de 53 casos registrados nos anos de 1910 a 1914; gastroenterite com 104 casos registrados no mesmo período; infecção intestinal e impaludismo com 61 e 35 casos, respectivamente (VIANA, 2016, p. 50).

[...] Baseado no boletim de Estatística Demographo-sanitaria da cidade de Belém, de dezembro de 1911, que trata do número de óbitos da população, [...] existia um assustador índice de óbito de crianças. A mortalidade entre meninos atingia 11.260 (41,76\%), enquanto a de meninas representava $5.329(19,76 \%)$ (ALVES, 2015, p. 146 e 147).

Tanto Viana (2016) quanto Alves (2015) demonstram em dados levantados do início do século XX que a mortalidade infantil estava associada aos interesses políticos econômicos e sociais vividos na capital paraense. É importante ressaltar que as ações higienistas para a manutenção e assistência à vida de crianças pobres, desvalidas e órfãs precisavam ser pensadas. Por isso, houve um conjunto de interesse de poderes associados aos princípios de higiene e reforma urbana em preservar o "bem estar" social e sanear as cidades por meio da educação higienista.

A mortalidade infantil foi alvo da preocupação nacional no final do século XIX e início do século XX, sobretudo quando os cuidados com as crianças e com a infância passam a ganhar destaque. 
Segundo Del Priore (2000, p.7), “a história da criança fez-se à sombra daquela dos adultos”, o que significa dizer que nem sempre as crianças foram vistas em sua especificidade, mas sim como aqueles sujeitos à margem das relações adultas, tornando-se secundários no seio familiar. Neste sentido, por não serem tidas como uma categoria social relevante pouco foi a preocupação em registrar as particularidades da realidade infantil.

Alves (2013), em estudos feitos sobre as obras de Gilberto Freyre "Casa Grande \& Senzala" e "Vida Social em Meados do século XIX", aponta que a mortalidade infantil foi enorme entre as populações indígenas desde o século XVI. Segundo a referida autora, a mortalidade infantil no Brasil continuou impressionante até o século XVIII. Porém, suas considerações corroboram com os estudos culturais assegurando que os hábitos europeus foram a causa da morte prematura de muitas crianças em virtude do clima brasileiro. Os hábitos trazidos da Europa como o rígido e supersticioso cuidado com o resguardo e o horror de banho, eram noções extremamente nocivas às crianças em clima quente.

\section{MORTALIDADE INFANTIL: VELÓRIO E SEPULTAMENTO DE “ANJINHOS”}

A idealização de que foram objeto os meninos filhos dos índios nos primeiros tempos da catequese e da colonização-época, precisamente, de elevada mortalidade infantil [...] tomou muitas vezes caráter meio mórbido; resultado, talvez, da identificação da criança como o anjo católico. A morte da criança passou a ser recebida quase com alegria; pelo menos sem horror (FREYRE, 2013.

Os rituais do velório e do sepultamento de crianças são atenuados a partir do início do século XIX, quando passa a ser um ato muito mais voluntário do que obrigatório (ARIÈS, 2003. p. 249). Este autor pontua ainda que o ato de reclusão tivera que ser conciliado com os hábitos de veneração/exaltação do morto, isto é, atitudes mais comuns entre as crianças, sobretudo aquelas que sofriam mortes prematuras ou com requintes de violência.

Em levantamentos feitos pelo grupo $\operatorname{ECOS}^{12}$, pudemos observar que o quantitativo de estudos acerca da infância na Amazônia ainda é pouco, sobretudo aqueles que envolvem o quadro da

\footnotetext{
${ }^{12}$ O Grupo de Pesquisas Constituição do Sujeito, Cultura e Educação (ECOS), pertence ao grupo de pesquisadores do Instituto de Ciência da Educação da Universidade Federal do Pará e do Programa de Pós-Graduação em Educação da mesma universidade. Os pesquisadores desenvolvem estudos sobre história da infância na Amazônia Paraense na interface da História, Educação e Cultura. Tem desenvolvido dissertações e teses investigando práticas culturais na historiografia da infância Paraense.
} 
mortalidade infantil e sua relação com as práticas de rituais do velório e do sepultamento de crianças. Neste sentido, foi possível averiguar que no Pará não se tem estudos que se debrucem sobre os rituais de velório e sepultamento, o que não permite perceber como é que se materializava essa prática no contexto amazônico, que é permeado por crenças e superstições que são entrelaçadas pelas várias etnias e nacionalidades que constituíram o Estado.

Do levantamento bibliográfico que realizamos foi possível identificar que os rituais do velório e do sepultamento de crianças eram momentos de comoção social, não no sentido do pesar, da dor, do sofrimento, mas uma comoção no tocante a celebração, não a celebração da morte, mas a celebração da passagem da vida terrena para a vida "eterna/celestial", com a garantia de aceitação pela condição que a infância concedia à criança, cujo caráter era tido como puro, livre de pecados.

Alves (2013) em um de seus estudos acerca da infância no Pará traz ricas informações sobre os relatos de viajantes, encontradas na obra de Gilberto Freyre "Casa Grande e Senzala", quando este aponta o espanto com que eram tomados os viajantes diante das cenas fúnebres da morte de crianças no século XIX. A autora relata que os funerais das crianças eram como procissões triunfais e que os pequenos cadáveres eram arrumados com muito esmero para poder serem expostos.

Alves (2013) aponta ainda riqueza de detalhes sobre a ornamentação do corpo dos anjinhos, como denominado na obra de Freyre, para o momento em que estes seriam expostos à visitação como se pode ver na citação que segue.

\footnotetext{
Uma prática muito comum narrada pelos viajantes nos rituais fúnebres infantis era o de arrumar o "anjinho" de forma a lhe restituir o aspecto que tinha quando vivo, por intermédio da maquiagem. Geralmente a criança morta tinha faces e lábios pintadas em abundância de um rosa brilhante, resultando numa aparência de que a criança estava viva. Há outro artefato bastante recorrente nos funerais infantis relatado pelos viajantes era o pano branco bordado ou a toalha de renda sobre o caixão (ALVES, 2013, p 9).
}

O exposto pela autora nos permite compreender que o corpo da criança morta passava por todo um preparo antes de ser velada e que a associação da criança com os anjos, um elemento de cunho cultural, herdado da doutrina cristã católica, era forte e presente nestes momentos, pois o esforço era para que o corpo da criança se parecesse o mais possível com os de "anjos". A cultura entre as famílias eram de que morrer criança a salvação estava garantida e ainda se tinha a possibilidade de intercessão diante de Deus em favor de seus familiares (ALVES, 2013). 
Outro elemento recorrente nos velórios de crianças diz respeito às vestimentas e ao caixão, práticas adotadas pelas famílias no que concerne o preparo dos corpos para os rituais fúnebres. O hábito de vestir os corpos sem vida com roupas brancas, a ornamentação do caixão com flores e "geralmente com forro de tafetá branco ou cor de rosa com detalhes em prata" sugeriam a pureza virginal da criança e apontavam também para a religiosidade, pois "o branco estava também associado à imagem de Nossa Senhora da Conceição" Alves (2013, p. 9).

Cortejo fúnebre era o ponto alto da participação coletiva. Geralmente toda a cidade era chamada a participar do ritual de cortejo. Segundo Gilberto Freyre, diferentemente dos adultos, nos funerais infantis a criança era levada de dia, lugar do cotidiano, do familiar. As procissões diurnas eram índice de que se dava por garantia de salvação e a de louvar o pequeno falecido (ALVES, 2013, p).

Ao contrário do que se imagina, em geral a morte não provocava dor, choro e pesar profundo por parte dos familiares. As cenas relatadas pelos viajantes que estiveram no Brasil no século XIX indicam que a vestimenta dos "anjinhos" era com cores alegres e parecia mais com festivais do que necessariamente com funerais, em razão dos artefatos e adereços que cobriam o defuntinho. Os cortejos fúnebres das crianças eram feitos durante o dia, rodeado de pessoas que "festejavam junto aos familiares" a despedida do anjinho. A despedida da criança, segundo Alves (2013), seguia um ritual de celebrar a morte da criança de maneira tranquila e principalmente de demonstrar respeito à vontade divina, uma vez que a "salvação estava garantida para a criança". Obviamente que os rituais de velório e sepultamento estavam diretamente relacionados às condições sociais e econômicas das crianças. As famílias abastadas recorriam a um ritual pomposo de despedida à criança, enquanto que as famílias pobres seguiam um ritual mais simples. Essa diferença ficava evidente nos aparatos religiosos e nos trajes dos defuntinhos. Havia ainda um aparato na preparação dos anjinhos para o velório. Geralmente, as famílias da elite paraense seguiam um ritual que deixava o pequeno defunto com ar singelo. As vestimentas e adereços seguiam aos desejos da família, que se fosse muito católica, preferiam tecidos claros como branco, rosa e azul para representar a docilidade e pureza da criança falecida. Os adereços colocados na criança iam desde medalhas de santos, até joias de família ou qualquer amuleto de crença da família, dos pais e padrinhos. Já as crianças de famílias pobres eram comuns serem veladas com mortalhas brancas que eram confeccionadas exclusivamente para elas. O ritual fúnebre era seguido por um cortejo acompanhado de crianças que precisava se despedir do 
anjinho. Esse translado até o cemitério era uma forma de toda população se despedir da criança e se compadecer com a dor e sofrimento da família

Outro fato relevante quanto a morte infantil em Belém do Pará são os registros em jornais anunciando o falecimento da criança. Em geral era feito pelas famílias abastadas ou ainda de amigos das famílias enlutadas que comunicavam à sociedade o falecimento da criança, mas também uma mensagem de carinho e afeto em virtude da perda tão prematura da criança.

\footnotetext{
Sabe-se também que as famílias mais abastadas não só publicavam nos jornais a perda de um anti-querido como recebiam inúmeras manifestações públicas de carinho e afeto neste momento de perda, de sofrimento e de dor. Geralmente as mensagens de condolência eram encontradas com muita facilidade nos jornais. Recorrentemente essas mensagens eram cheias de elogios ao morto, evidenciavam as qualidades do falecido. As crianças sempre eram vistas, como meigas, doces, puras, verdadeiros anjos, tão boas que Deus por sua imensa misericórdia as tomou para si de modo que as mesmas não sofressem nesse mundo de aflição (ALVES, 2013, p. 12).
}

Os achados sobre os rituais de velório e sepultamento de crianças em Belém do Pará indicam que havia uma relação da morte com a infância na preparação do corpo das crianças, mas também o papel da família nos rituais de morte.

\section{CONSIDERAÇÕES FINAIS}

A partir da problematização que se buscou fazer neste estudo apontamos algumas considerações sobre o tema, pois embora a pesquisa esteja em desenvolvimento, inclusive nas buscas de documentos, foi possível fazer algumas inferências conclusivas acerca daquilo que fora encontrado até então.

A atuação dos médicos higienistas e sanitaristas revelam à cultura e educação contidas em suas ações, num esforço de preservar a infância e de contribuir com o progresso da nação que era almejada pelos republicanos da região norte. O presente artigo traz à baila a importância das políticas higienistas no combate à mortalidade infantil e de ações significativas que de certo modo diminuíram a morte de crianças no Brasil.

Sobre os rituais do velório de crianças foi possível constatar que havia forte influência do cristianismo católico, especialmente no processo de preparo do corpo das crianças mortas, que eram 
ornamentadas com adereços que remetiam as lembranças de santos. Havia, portanto, o uso de vestes brancas, cabelos cacheados, asas de anjos entre outros para compor a indumentária do defuntinho, com o objetivo de garantir a salvação no reino de Deus.

Com relação às pesquisas sobre os rituais diante da morte de crianças na Amazônia paraense é preciso compreender que muito ainda se tem a investigar, para que seja possível a consolidação destes estudos, uma vez que os materiais disponíveis para pesquisa ainda são escassos, sobretudo os referentes aos rituais do velório e do sepultamento de crianças. Contudo, é de suma importância reconhecer as contribuições dos trabalhos desenvolvidos pelo grupo ECOS, especialmente dos pesquisadores do Programa de Pós-Graduação em Educação da UFPA, pois suas produções são de grande relevância para os avanços sobre as práticas cultuais que se disseminaram na infância da região Norte. É indubitavelmente um estudo relevante para o campo da educação, pois corrobora com a ampliação da produção historiográfica da infância na Amazônia paraense. Enfim, este artigo aponta caminhos para novos estudos direcionados aos rituais da morte da criança em Belém do Pará nos séculos XIX e XX.

\section{REFERÊNCIAS}

ALVES, Laura Maria Silva Araújo. Em busca da Infância na Obra de Gilberto Freyre: do Império à República. Apresentado no $19^{\circ}$ Congresso Brasileiro de Educação Infantil da OMEP. São Luiz, 2013.

AMARAL, A. S. Vamos à vacina? Doenças, saúde e práticas médico-sanitárias em Belém (104 - 1911). Dissertação (Mestrado em História Social da Amazônia). Universidade Federal do Pará, Belém, 2006.

ARIÈS, P. História social da criança e da família. Rio de Janeiro, Zahar, 1981.

ARIÈS, P. História da morte no ocidente. Rio de Janeiro, Ediouro, 2003.

DEL PRIORE, M. (org.). História das crianças no Brasil, São Paulo: Contexto, 2000.

FIGUEIREDO, Aldrin Moura de. Tesouros da memória: História e patrimônio no Grão-Pará. Belém: Ministério da Fazenda. Gerência Regional de Administração no Pará/Museu de Arte de Belém, 2009.

FREYRE. Gilberto. Vida social no Brasil nos meados do século XIX. 4 ed. Revista. São Paulo: Global, 2008.

FREYRE. Gilberto. Casa-Grande e senzala: formação da família brasileira sob o regime patriarcal. 52 ed. São Paulo: Global, 2013.

GÓIS JR, Edivaldo; LOVISOLO, Hugo Rodolfo. Descontinuidades e continuidades do movimento higienista no Brasil do século XX. Rev. Bras. Cienc. Esporte, Campinas, v. 25, n. 1, p. 41-54. 2003

GUIMARÃES, Jacqueline Tatiane da S. A educação e os cuidados com a criança (1915-1955): uma análise bakhtiniana dos discursos dos médicos do estado do Pará. Tese (Doutorado) - Universidade Federal do Pará, Programa de PósGraduação em Educação, 2016.

HEYWOOD, C. Uma história da infância: da Idade Média á época contemporânea no Ocidente. Porto Alegre: Artmed, 2004.

MELO; NASCIMENTO at al. 2012. A mortalidade Infantil e as Medidas de Assistência e Cuidado a criança na Belém da Belle Époque (1910 - 1915). Disponível em: <http://sbhe.org.br/novo/congressos/cbhe7/pdf/07$\% 20$ HISTORIA\%20DAS\%20INSTITUICOES\%20E\%20PRATICAS\%20EDUCATIVAS/A\%20POLITICA\%20HIGI 
ENISTA\%20NO\%20PARA\%20DA\%20BELLE\%20EPOQUE\%20E\%20A\%20PROTECAO\%20A\%20INFANCIA $\% 2$ OPOBRE\%20EM\%201912.pdf>. Acesso em: 01 out. de 2015.

PINHEIRO Welington da Costa. A infância nas páginas de jornal: discursos (re) produzidos pela imprensa paraense na primeira década do século XX. Dissertação (Mestrado) - Universidade Federal do Pará, Programa de pós-Graduação em Educação, 2013.

PONTE, Carlos Fidelis. O Sanitarismo e os projetos de nação. In: PONTE, Carlos Fidelis et. Al. O sanitarismo (re) descobre o Brasil. Rio de Janeiro: Fundação Oswaldo Cruz, 2007. Disponível em:<http://www.observatorio.epsjv.fiocruz.br/upload/na\%20corda\%20bamba/cap_3.pdf>. Acesso em:29 mai. 2016

RIZZINI, I. O Século Perdido. Raízes históricas das políticas públicas para a infância no Brasil. São Paulo: Cortez, 2009.

RIZZINI. Irene; PILOTTI, Francisco. A arte de governar crianças: a história das políticas sociais, da legislação e da assistência à infância no Brasil. $2^{\mathrm{a}}$ ed. São Paulo: Cortez, 2009.

SÁ-SILVA. Jackson Ronie; ALMEIDA, Cristóvão Domingos de; GUINDANI, Joel Felipe. Pesquisa documental: pistas teóricas e metodológicas. Revista Brasileira de História \& Ciências Sociais. Ano I - Número I - Julho de 2009. Disponível em: <https//: www.rbhcs.com> ISSN: 2175-3423. Acesso em: 14 set. 2016.

VIANA, Carmeci dos Reis. A Mortalidade Infantil e a Política Higienista em Belém do Pará (1910 - 1914): Um estudo nos Livros Perpétuos de Sepultamento de Crianças do Cemitério de Santa Isabel. Monografia (Graduação) - Universidade Federal do Pará, Instituto de Ciências da Educação, Faculdade de Educação, 2016. 


\section{RITOS DE VELÓRIO E SEPULTAMENTO DE CRIANÇAS NA HISTÓRIA DA INFÂNCIA EM BELÉM DO PARÁ} (1910-1914)

RESUMO :O presente artigo aborda inserções iniciais da pesquisa que está sendo desenvolvida na dissertação de Mestrado no Programa de Pós-Graduação em Educação que investiga os rituais do velório e do sepultamento de crianças em Belém do Pará (1910 e 1914). De cunho bibliográfico, esta pesquisa foi desenvolvida a partir de um levantamento de autores que abordam a mortalidade infantil e as práticas culturais no ritual de despedida da criança na morte. Os objetivos que norteiam o artigo foram: (1) destacar aspectos da mortalidade infantil e os rituais do velório e do sepultamento de crianças em Belém do Pará; (2) apontar a relação dos rituais do velório e do sepultamento de crianças com o mito de veneração da alma dos anjinhos. Os resultados preliminares apontam que a mortalidade infantil era o grande flagelo no início da República e que os rituais de preparação do corpo, do velório e o do sepultamento estavam relacionados ao ideário religioso de que morrer anjinho era sinal de purificação da alma. Os dados revelam ainda que, de um lado, os ritos do velório e do sepultamento da criança estavam interligados ao nível sócio econômico da criança e da religiosidade dos seus familiares, e de outro, do rito de veneração da criança morta a partir dos aparatos e artefatos que davam ao anjinho um ar de docilidade e pureza.

Palavras chave: História da Infância. Mortalidade Infantil. Velório e Sepultamento.

\section{RUDES OF VELORUS AND SEPULTY OF CHILDREN IN THE HISTORY OF CHILDREN IN BELÉM DO PARÁ (1910-1914).}

ABSTRACT: This article discusses the initial insertions of the research that is being developed in the Master's thesis in the Graduate Program in Education that investigates the rituals of the funeral and burial of children in Belém of Pará (1910 and 1914). From a bibliographical point of view, this research was developed from a survey of authors that deal with infant mortality and cultural practices in the ritual of farewell to the child in death. The objectives that guided the article were: (1) to highlight aspects of infant mortality and the rituals of the wake and burial of children in Belém of Pará; (2) to point out the relation between the rituals of the wake and the burial of children with the myth of veneration of the souls of the angels. The preliminary results indicate that infant mortality was the great scourge at the beginning of the Republic and that the rituals of preparation of the body, the wake and the burial were related to the religious idea that to die angel was a sign of purification of the soul. The data also reveal that, on the one hand, the rites of the wake and the burial of the child were interconnected to the socioeconomic level of the child and the religiosity of their relatives, and on the other, the rite of veneration of the dead child from the apparatuses and artifacts that gave the angel an air of docility and purity.

Keywords: History of Childhood. Child mortality. Worship and Burial.

\section{RITOS DE VELORIO Y SEPULTAMIENTO DE NIÑOS EN LA HISTORIA DE LA INFANCIA EN BELÉM DEL PARÁ (1910-1914)}

RESUMEN: El presente artículo aborda inserciones iniciales de la investigación que se está desarrollando en la disertación de Maestría en el Programa de Postgrado en Educación que investiga los rituales del velatorio y del sepultamiento de niños en Belém do Pará (1910 y 1914). De esta bibliografía, esta investigación fue desarrollada a partir de un levantamiento de autores que abordan la mortalidad infantil y las prácticas culturales en el ritual de despedida del niño en la muerte. Los objetivos que guían el trabajo fueron: (1) los aspectos más destacados de la mortalidad infantil y los rituales del funeral y el entierro de los niños en Belem; (2) señalar la relación de los rituales del velorio y del sepultamiento de niños con el mito de veneración del alma de los ángeles. Los resultados preliminares apuntan que la mortalidad infantil era el gran flagelo al inicio de la República y que los rituales de preparación del cuerpo, del velorio y del sepultamiento estaban relacionados al ideario religioso de que morir el anciano era signo de purificación del alma. Los datos revelan que, por un lado, los ritos del velatorio y del sepultamiento del niño estaban interconectados al nivel socioeconómico del niño y de la religiosidad de sus familiares, y de otro, del rito de veneración del niño muerto a partir de los aparatos y artefactos que daban al anhelo un aire de docilidad y pureza.

Palabras clave: Historia de la infancia. Mortalidad infantil. Velero y Sepulto. 